\title{
Living by numbers
}

\author{
Dirk Van Raemdonck, MD, PhD, ${ }^{a}$ Arne Neyrinck, $\mathrm{MD}, \mathrm{PhD},{ }^{\mathrm{b}}$ Robin Vos, $\mathrm{MD}, \mathrm{PhD},{ }^{\mathrm{c}}$ and \\ Geert M. Verleden, MD, $\mathrm{PhD}^{\mathrm{c}}$
}

\author{
From the Departments of ${ }^{\mathrm{a}}$ Thoracic Surgery, ${ }^{\mathrm{b}}$ Anesthesiology, and ${ }^{\mathrm{c}}$ Pneumology, University Hospitals Leuven, \\ Leuven, Belgium. \\ Disclosures: Authors have nothing to disclose with regard to commercial support. \\ Received for publication April 3, 2018; accepted for publication April 5, 2018; available ahead of print May 10, \\ 2018 . \\ Address for reprints: Dirk Van Raemdonck, MD, PhD, Department of Thoracic Surgery, University Hospital Gas- \\ thuisberg, Herestraat 49, Leuven B-3000, Belgium (E-mail: dirk.vanraemdonck@uzleuven.be). \\ J Thorac Cardiovasc Surg 2018;156:906-7 \\ $0022-5223 / \$ 36.00$ \\ Copyright (c) 2018 by The American Association for Thoracic Surgery \\ https://doi.org/10.1016/j.jtcvs.2018.04.002
}

"Living by Numbers" is a song performed by the English synthpop group New Musik. ${ }^{1}$ It was the band's biggest hit worldwide in 1980, before the first reports on successful lung transplantation (LTx). The expression "living by numbers" asks the question of whether a problem might best be approached qualitatively or quantitatively.

According to the 2017 Registry Report of the International Society for Heart and Lung Transplantation, ${ }^{2}$ center volume is an independent risk factor for 1-year mortality among recipients undergoing LTx for chronic obstructive pulmonary disease and idiopathic interstitial pneumonia. In a study published in 2009 on more than 10,000 cases in the United Network for Organ Sharing database, Weiss and associates ${ }^{3}$ analyzed the impact of center volume on posttransplant outcome. Low-volume centers had double the risk of 30-day censored 1-year mortality. High-volume centers ( $>20$ LTx procedures/year) had the lowest 30-day mortality $(4.1 \%)$. Weiss and associates ${ }^{3}$ concluded that low center volume was associated with increased shortterm and cumulative mortalities despite fewer patients with idiopathic pulmonary fibrosis and younger patients. As for many other complex thoracic surgical procedures with high risk of mortality, center volume and surgeon specialty are important determinants of outcome, but evidencebased minimum-volume standards are lacking. ${ }^{4-6}$

In this issue of the Journal, Balsara and coworkers ${ }^{7}$ report their review of 1500 adult LTx procedures performed Louis, comparing recipient outcomes before and after the introduction of the lung allocation score in 2005. When comparing demographic characteristics between the study groups (April 1988-April 2005, $\mathrm{n}=792$; May 2005September 2016; $\mathrm{n}=708$ ), the average age at transplant increased from $48 \pm 13$ years to $50 \pm 14$ years, the percentage of male patients increased from $51 \%$ to $59 \%$, and the number of double-lung transplants increased from $77.7 \%$ to $96.2 \%$. The percentage of recipients with emphysema decreased from $52 \%$ to $25.8 \%$, whereas the percentage of between 1998 and 2016 at Washington University in St

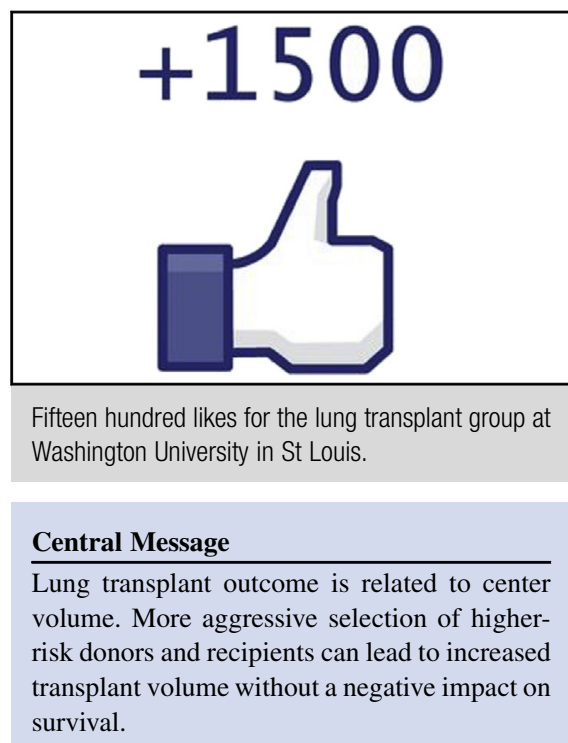

See Article page 894 recipients with pulmonary fibrosis increased from $16.1 \%$ to $46 \%$ as a result of prioritization with higher lung allocation score. Overall incidence of grade 3 primary graft dysfunction was significantly lower in the first cohort at $22.1 \%$, compared with $31.6 \%$ in the second $(P<.001)$. Nonetheless, overall in-hospital mortality did not differ $(4.4 \%$ vs $3.5 \%)$. A significant improvement in 1-year survival was noted, from $81.6 \%$ to $91.4 \%(P<.02)$. Balsara and coworkers ${ }^{7}$ concluded that more aggressive selection of higher-risk donors and recipients can lead to increased transplant volume without a negative impact on survival. Although their improved survival though the years is likely to be multifactorial, better understanding and management of early (primary graft dysfunction) and long-term (chronic lung allograft dysfunction) dysfunction are certainly key elements in their success.

This is the largest single-center report to date on outcome in lung recipients undergoing LTx over the span of 3 decades. The St Louis LTx group is to be applauded for these improved survival results in the post-lung allocation score era. Other LTx centers have learned many aspects from this pioneering group. We are grateful to their initial surgical leaders, Joel D. Cooper and G. Alexander Patterson, who moved from Toronto to St Louis, for showing the way forward in isolated LTx.

In our series of 1036 patients who underwent LTx at the University Hospitals Leuven, Belgium, between 1991 and 

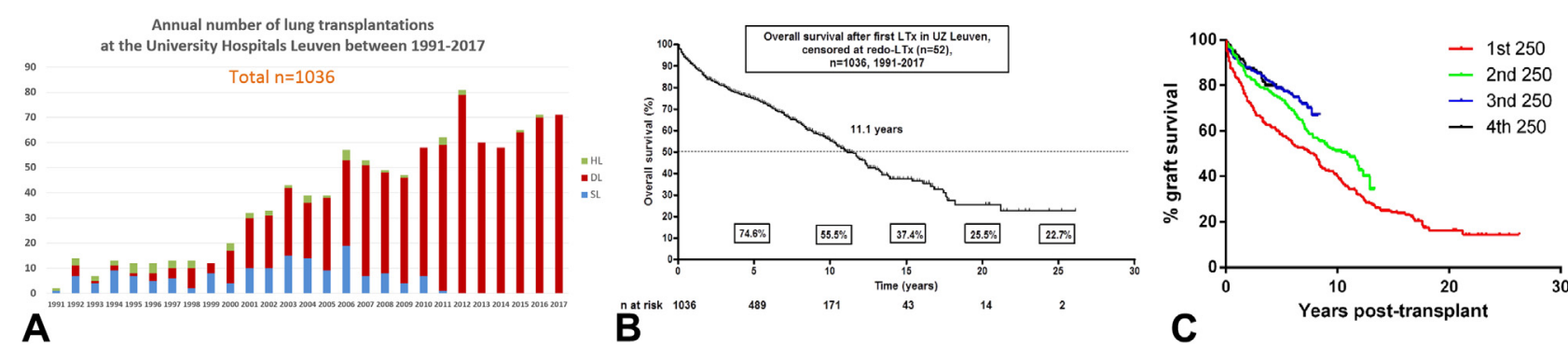

FIGURE 1. A, Evolution in annual number and transplant type of more than 1000 lung transplants performed at the University Hospitals Leuven, Belgium between July 14, 1991, and December 31, 2017. B, Overall lung transplant (LTx) graft survival (censored at redo lung transplantation). UZ Leuven, Universitaire Ziekenhuizen Leuven (University Hospitals Leuven). C, Graft survival in the first 1000 lung transplant patients stratified per quartile. Results improved significantly with growing experience over time: quartile 1 versus quartile $4(P<.0001$; hazard ratio, 2.311 ; $95 \%$ confidence interval, 1.583 $3.375)$; quartile 2 versus quartile $4(P=.013$; hazard ratio, $1.627 ; 95 \%$ confidence interval, $1.105-2.395)$; quartile 3 versus quartile $4(P=.50$; hazard ratio, 1.154; 95\% confidence interval, 0.763-1.745). $H L$, Heart-lung transplant; $D L$, double-lung transplant; $S L$, single-lung transplant.

2017, a gradual shift was noticed from single-lung transplantation in the first half of our program toward doublelung transplantation in most patients in the second half and to the exclusive use of both lungs for a single recipient since 2012 (Figure 1, A). Median survival was 11 years, and overall graft survivals censored at redo-LTx were $90.3 \%$, $80.7 \%, 74.6 \%, 55.5 \%$, and $25.5 \%$ at $1,3,5,10$, and 20 years (Figure 1,B). Survival improved significantly with growing numbers and total experience of the transplant team (Figure 1,C). Undoubtedly, improved surgical techniques, better immunosuppression and infection prophylaxis, and earlier recognition and better management of both primary graft dysfunction and chronic lung allograft dysfunction have largely influenced our results over time. The use of lungs from extended-criteria donors, ${ }^{8}$ lungs from donors after circulatory death, ${ }^{9}$ and cadaveric lobar LTx,${ }^{10}$ did not negatively affect survival in our cohort. Much as in the report of Balsara and coworkers, ${ }^{7}$ these donors helped us to increase our transplant volume in Leuven with better survival over time.

This article from St Louis ${ }^{7}$ nicely demonstrates that quality and quantity go hand in hand in LTx. It takes years and years, and a high level of expertise, to come even close to perfection.

We thank L. Ceulemans, MD, PhD, and S. E. Verleden, MSc, $\mathrm{PhD}$, for help with Figure 1.

\section{References}

1. Living by numbers. Available at: https://en.wikipedia.org/wiki/Living_by_ Numbers. Accessed March 31, 2018.

2. Chambers DC, Yusen RD, Cherikh WS, Goldfarb SB, Kucheryavaya AY, Khusch K, et al. International Society for Heart and Lung Transplantation. The registry of the International Society for Heart and Lung Transplantation: Thirty-fourth adult lung and heart-lung transplantation report-2017, focus theme: allograft ischemic time. J Heart Lung Transplant. 2017;36 1047-59.

3. Weiss ES, Allen JG, Meguid RA, Patel ND, Merlo CA, Orens JB, et al. The impact of center volume on survival in lung transplantation: an analysis of more than 10,000 cases. Ann Thorac Surg. 2009:88:1062-70.

4. Birkmeyer JD, Stukel TA, Siewers AE, Goodney PP, Wennberg DE, Lucas FL. Surgical volume and operative mortality in the United States. $N$ Engl J Med. 2003;349:2117-27.

5. Farjah F, Flum DR, Varghese TK Jr, Symons RG, Wood DE. Surgeon specialty and long-term survival after pulmonary resection for lung cancer. Ann Thorac Surg. 2009;87:995-1004.

6. von Meyenfeldt EM, Gooiker GA, van Gijn W, Post PN, van de Velde CJ, Tollenaar RA, et al. The relationship between volume or surgeon specialty and outcome in the surgical treatment of lung cancer: a systematic review and meta-analysis. J Thorac Oncol. 2012;7:1170-8.

7. Balsara KR, Krupnick AS, Bell JM, Khiabani A, Scavuzzo M, Hachem R, et al. A single center experience of 1500 lung transplant patients. J Thorac Cardiovasc Surg. 2018;156:894-905.e3.

8. Somers J, Ruttens D, Verleden SE, Cox B, Stanzi A, Vandermeulen E, et al. A decade of extended-criteria lung donors in a single-center: was it justified? Transpl Int. 2015;28:170-9.

9. Ruttens D, Martens A, Ordies S, Verleden SE, Neyrinck AP, Vos R, et al. Short- and long-term outcomes after lung transplantation from circulatorydead donors: a single-center experience. Transplantation. 2017;101: 2691-4.

10. Stanzi A, Decaluwe H, Coosemans W, De Leyn P, Nafteux P, Van Veer H, et al. Lobar lung transplantation from deceased donors: a valid option for small-sized patients with cystic fibrosis. Transplant Proc. 2014;46:3154-9. 